\title{
Long-term results of surgical correction of pectus excavatum and sternal prominence
}

\author{
K. M O G H IS S I \\ From Southampton Chest Hospital
}

In 1957, from this unit, the late E. F. Chin published a paper on 'Surgery of funnel chest and congenital sternal prominence'. He gave details concerning the aetiology and symptomatology of the condition. The paper was based on his work and experience of 54 cases. Because of Chin's particular interest in these conditions, many more patients have been referred to us and have been operated on here; and it has been possible to watch the progress of patients operated on since 1952. In his paper Chin had 21 cases which had been followed for two years or more, but none of these had been followed up for four to five years.

The object of the present paper is to review the long-term follow-up of the patients operated upon, and, in the light of this, to discuss the possible aetiology of the conditions. Particular emphasis will be given to the failures and recurrences.

\section{MATERIAL AND METHOD}

Some 100 patients with chest deformity have been operated upon in this unit. We review here 64 cases of pectus excavatum and pectus carinatum operated upon between 1953 and 1957. The more recent cases have not been considered in this paper for two reasons: (1) that for that period only, the operation was performed more uniformly according to Ravitch's (1949, 1956) method and slightly modified by Chin ; and (2) that most papers published about this subject deal with all aspects of the problem, but the longterm results have not been assessed. For such an essentially asymptomatic condition, results should be judged over four or five years and not six months.

It will be seen that the deformity, when it recurs, does not do so for three or four years after operation.

OPERATION A longitudinal or transverse incision is used; it extends from the level of the second costal cartilage to below the xiphoid if it is longitudinal, of to the nipple line at about the level of the fourth ow fifth costal cartilage if it is transverse. Deformed costas cartilages are resected to just beyond the site of angue lation. Any perichondrial layer which holds the sternum is severed from the sternum. The xiphoid is detached and covered by the rectus sheath. ThE sternum is drilled above and below the ostectomy with two pairs of drill holes, and linen thread if passed through these; secure fixation is obtained witlp the sternum held in the overcorrected position. The retrosternal space is drained to an underwater seal.

Our method of reviewing has been facilitated by appraising the results in the follow-up clinics an by repeated clinical photographs of patients' chest\$ during their attendances. Thus the judgment of the results has been as accurate as possible. A normal looking chest was taken as $100 \% ; 90 \%$ to $100 \%$ 을 $70 \%$ to $90 \%$, or less than $65 \%$ indicated good, fair or bad results, respectively.

The results have been based entirely on cosmetic grounds.

The 64 cases reviewed fall into three categories? Group $A$ Twenty-four patients with pectus excavatum were operated upon between 1952 an 1954, providing an eight- to 10-year follow-up.

Group $B$ Thirty-four patients with pectus excavaturg were operated upon between 1955 and 1957, providing a five- to seven-year follow-up.

Group $C$ Six patients had pectus carinatum (sternaำ prominence).

RESULTS

Chin classified the funnel chest deformity aßs follows.

TYPE 1 This is a localized deformity, symK metrical on both sides. Angulation of the costaf margin is acute and occurs inside the nipple line

TYPE 2 This is a more diffuse deformity, higher in extent, but still symmetrical on both sides.

TYPE 3 This is an asymmetrical deformity Sternal depression and angulation of the ribs are्ष both more pronounced on one side.

This classification of the shape and extent is true, and the photographs confirm this. In the 
immediate post-operative results there are differences in the three types.

The following assessment by Chin indicates much better results for the patients with a type 1 deformity than for the others (Table I).

TABLE I

\begin{tabular}{c|c|c|c|c}
\hline \multirow{2}{*}{ Type } & \multicolumn{3}{|c|}{ Result } & Total \\
\cline { 2 - 4 } & Good & Fair & Bad & \\
\hline 1 & 19 & 3 & 2 & 24 \\
2 & 1 & 9 & 3 & 13 \\
3 & 1 & 3 & & 4 \\
\hline
\end{tabular}

Table II shows the long-term results for all patients in groups $\mathbf{A}$ and $\mathbf{B}$.

T ABLE II

\begin{tabular}{c|c|c|c|c}
\hline \multirow{2}{*}{ Type } & \multicolumn{3}{|c|}{ Result } & Total \\
\cline { 2 - 5 } & Good & Fair & Bad & \\
\hline 1 & 20 & 15 & 10 & 45 \\
2 & 3 & 1 & 1 & 5 \\
3 & 4 & 2 & 2 & 8 \\
\hline
\end{tabular}

The results for type 1 seem no better than those for type 3, so we have not divided our cases into these three types (Tables III and IV).

TABLE III

GROUP A CASES

\begin{tabular}{|c|c|c|c|c|}
\hline & Results & & Number & Percent \\
\hline \multirow[t]{2}{*}{$\begin{array}{l}\text { Good } \\
\text { Fair } \\
\text { Bad }\end{array}$} & $\begin{array}{ll}. & \\
\cdots & \\
. & \end{array}$ & $\begin{array}{l}. . \\
\ldots\end{array}$ & $\begin{array}{r}10 \\
5 \\
9\end{array}$ & $\begin{array}{l}41 \cdot 7 \\
20 \cdot 8 \\
37 \cdot 5\end{array}$ \\
\hline & Total & .. & 24 & \\
\hline
\end{tabular}

TABLE IV

GROUP B CASES

\begin{tabular}{llll|c|c}
\hline \multicolumn{3}{c|}{ Results } & & Number & Percent \\
\hline Good & $\ldots$ & $\ldots$ & $\ldots$ & 17 & 50 \\
Fair & $\ldots$ & $\ldots$ & $\ldots$ & 13 & $38 \cdot 3$ \\
Bad & $\cdots$ & $\ldots$ & $\cdots$ & 4 & $11 \cdot 7$ \\
\hline & \multicolumn{2}{c}{ Total } & $\ldots$ & 34 & \\
\hline
\end{tabular}

\section{DISCUSSION}

One point is at once clear ; whereas in the fiveto seven-year follow-up there are four bad cases and 13 fair out of a total of 34 cases, in the longer period of follow-up there are nine bad cases and five fair out of 24 cases. It is reasonable to draw the conclusion that the recurrence is gradual and that some of the good immediate results become fair after four to seven years and become bad after eight to 10 years. It is also clear that the result of operation can be considered good only after seven years and not after six months or a year.

Table $\mathrm{V}$ shows cases in group $\mathrm{A}$ which have a complete recurrence of the deformity at present. Only two out of nine had bad immediate results.

TABLE V

RECURRENT CASES IN GROUP A (Operated on between 1952 and 1954)

\begin{tabular}{|c|c|c|c|}
\hline Age & $\begin{array}{l}\text { Date of } \\
\text { Operation }\end{array}$ & $\underset{\text { Result }}{\text { Immediate }}$ & $\begin{array}{l}\text { Approx. Date of } \\
\text { Regression }\end{array}$ \\
\hline $\begin{array}{c}4 \frac{1}{2} \\
5 \\
10 \\
14 \\
24 \\
2 \\
28 \\
17 \text { mth. } \\
19 \text {,, }\end{array}$ & $\begin{array}{l}1954 \\
1954 \\
1953 \\
1954 \\
1954 \\
1954 \\
1954 \\
1952 \\
1954\end{array}$ & $\begin{array}{l}\text { Very good } \\
\text { Fair to" good } \\
\text { Good } \\
\text { ", } \\
\text { Fair to good } \\
\text { Bad } \\
\text {," }\end{array}$ & $\begin{array}{l}1957-8 \\
1957-8 \\
1958 \\
1959 \\
1958 \\
1958 \\
1958\end{array}$ \\
\hline
\end{tabular}

The remainder had a good result at the beginning but later regressed. The two patients with bad immediate results were under 2 years of age. Regression usually started about four years after operation.

The following is a typical example.

Case 1, a child aged $4 \frac{1}{2}$ years, was operated on at the beginning of 1954 for a severe type of deformity (Fig. 1a). The result was judged as $100 \%$ immediately after operation (Fig. 1b), and for the following year or two. At the end of 1957 the result was $70 \%$ to $80 \%$, which we classify as fair (Fig. 1c), but in 1962 there was a complete recurrence of the deformity (Fig. 1d).

T A B LE V I

RECURRENT CASES IN GROUP B (Operated on between 1955 and 1957)

\begin{tabular}{c|c|c|c}
\hline Age & $\begin{array}{c}\text { Date of } \\
\text { Operation }\end{array}$ & $\begin{array}{c}\text { Immediate } \\
\text { Result }\end{array}$ & $\begin{array}{c}\text { Ultimate } \\
\text { Result }\end{array}$ \\
\hline 15 & 1957 & Fair & Bad \\
52 & 1956 & Good &, \\
$2 \frac{1}{2}$ & 1956 & Bad &, \\
\hline
\end{tabular}

In group B only one case had a good immediate result, others had fair or bad results (Table VI), and we have no precise data as to the approximate time of regression. The only bad case at the time of the original operation was that of a child aged $2 \frac{1}{2}$ years. We conclude that in recurrent cases regression starts at about the fourth or fifth year after operation and progresses gradually. After eight to nine years these cases become a complete failure. 
FIG. 1a. Pectus excavatum deformity.

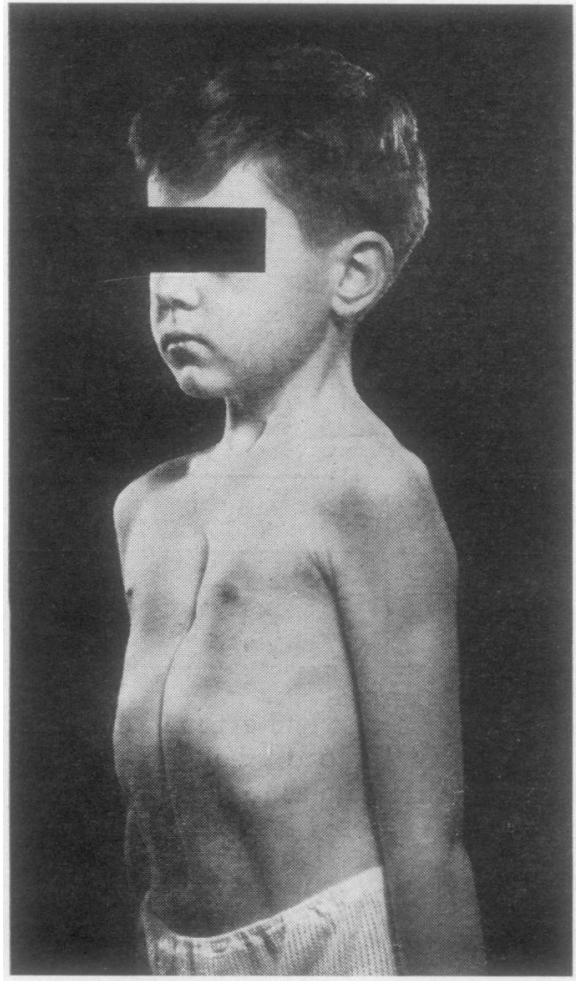

FIG. 1c. The same child in 1957 with some regression of the deformity.

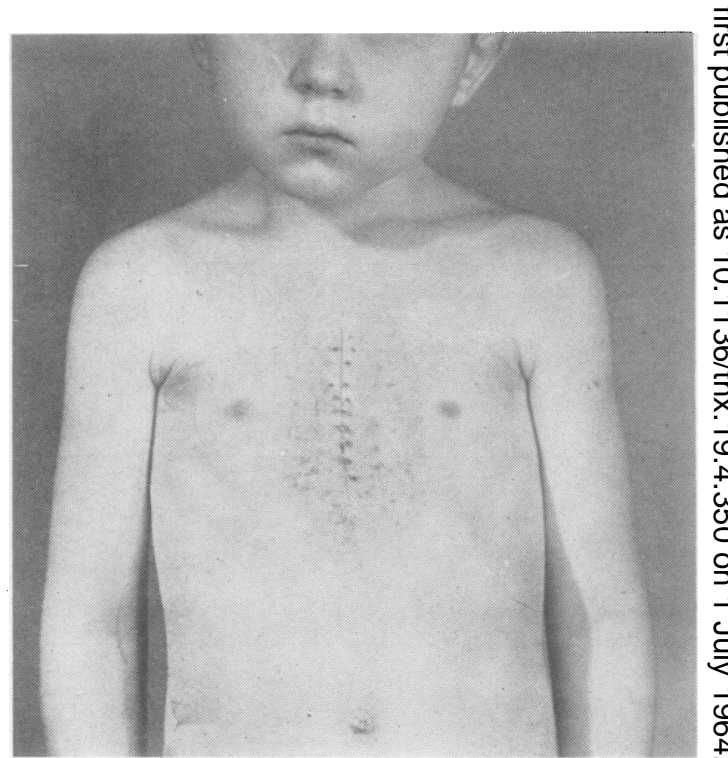

FIG. 1b. After operation the result is good.

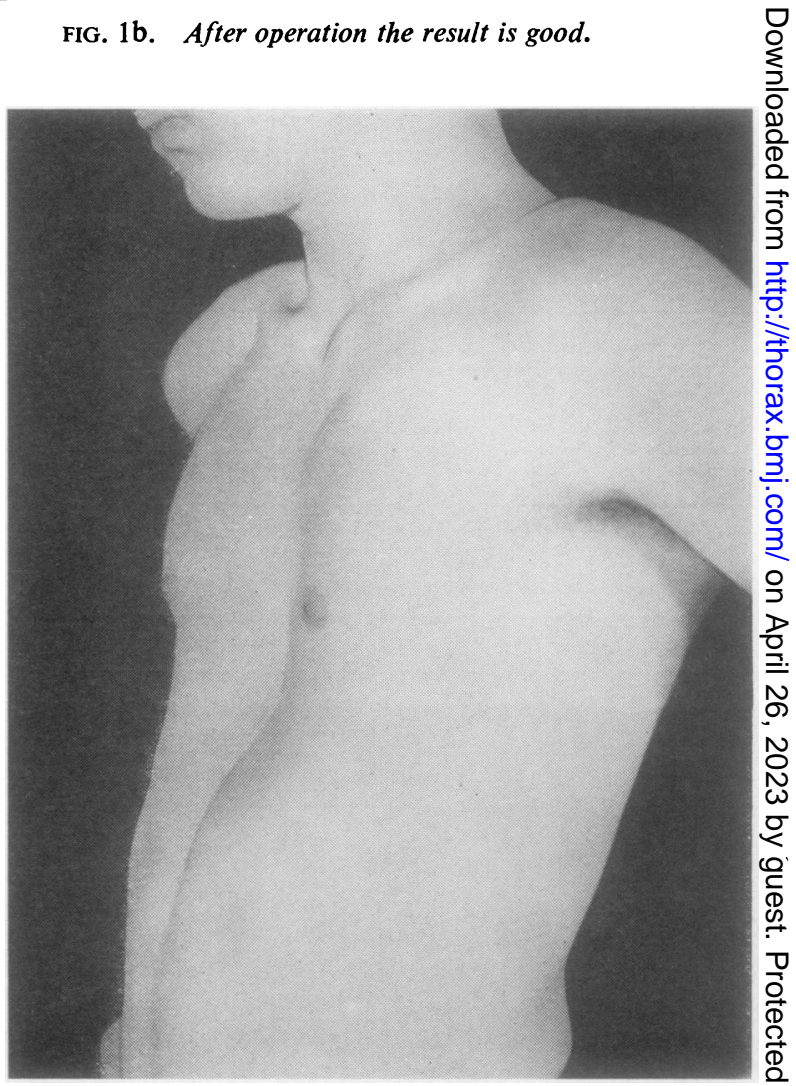

FIG. 1d. The same child, now aged 14 years, showing complete recurrence of the deformity.

Q 융 
There are 18 cases with fair results in groups $\mathrm{A}$ and $B$. Twelve of these had a good result immediately after operation. In the remaining six, the result was judged as $\mathbf{8 0} \%$ immediately after operation, and at present their results are fair (but approaching $65 \%$ ), i.e., although they were classified as fair in the immediate post-operative period, there has been a definite deterioration of the cosmetic result. In these cases it has been difficult to assess the deterioration in relation to the time following operation.

If the immediate result of an operation is judged as good, fair, and bad, the ultimate results can be approximately assessed. In the cases with a good immediate result, if there is a recurrence, it will occur after seven to eight years. In cases with a fair immediate result, the regression and recurrence set in earlier, at four to five years. We found no case in which the immediate result of operation was fair or bad and the long-term follow-up showed an improvement.

AETIOLOGY Pectus excavatum is stated to be a congenital deformity by most writers, including the late E. F. Chin, of this unit.

I could find no evidence from the present cases, and from other additional cases in this unit, that the deformity is congenital, nor is the literature on this subject convincing.

The ages at which the deformities were noticed in our 58 patients are as follows. In 23 cases out of 58 the deformity was noticed before the age of 2 years; in 16 the deformity was noticed after the age of 2 years. In the remaining 19 cases no date is recorded. Discarding the latter 19 cases, it is shown that in over one-third of the cases the deformity was not present before the age of 2 years. In only 17 out of 58 was the deformity noticed at birth. Therefore, if the deformity is congenital, it has not been noticed by the parents in well over two-thirds of the cases, and if the cause of the deformity was present at birth, its 'effect' was not seen in many until later in life.

As to the reasons for the recurrence of pectus excavatum after correction, we have no evidence. In our cases, the operations were all performed according to one method and mostly by one surgeon (the late E. F. Chin), and there were no significant post-operative complications in any of the patients. Chin favoured a diaphragmatic origin of the deformity. Together with Brodkin (1953), he believed the muscular deficiency of the anterior part of the diaphragm to be the prime factor in starting a chain of reactions, involving the bony and cartilaginous part of the anterior and lateral walls of the lower thorax, the end result being various degrees of funnel chest. In spite of the evidence given by supporters of this theory, there remains a weak point to be answered, and that is: What happens after four or five years to the cases that have been corrected? Why is it that some do well and others do not? At operation the lower costal cartilages are resected and the lower sternum is detached from its diaphragmatic attachment and mobilized. Then what makes for a recurrence; and why does it occur in some and not in others?

The reattachment of the lower sternum to the diaphragm might be evoked as the cause of the recurrence, but in three cases of recurrence reoperated on recently, no particular attachment was found between the two structures.

Respiratory embarrassment and infection in infants, together with dyspnoea and stridor, have been mentioned as the possible factor causing the deformity.

In the cases under review, the patients who had chest symptoms before operation generally lost their symptoms post-operatively, and when they developed a recurrence of the deformity they were still symptomless. Out of 14 cases in groups A and $B$ in our series, four had dyspnoea, repeated chest infection, and palpitations before operation, but they were free of symptoms within a year after operation. Nevertheless, though they were symptomless they developed a complete recurrence of the deformity. They prove that the airway embarrassment is not the cause of the recurrence, and they emphasize that the deformity by itself rarely causes respiratory symptoms.

Abnormalities of cartilage, and costal cartilages in particular, together with respiratory obstruction during neonatal life have been thought to cause the deformity. This seems reasonable enough to explain the cause of the deformity, as well as the reason for a recurrence. More detailed research along these lines is necessary to be able to prove or disprove the idea.

RELATION OF AGE AND LATE RESULTS The age of the patient at the time of operation is taken into consideration. Considerable disagreement exists as to the optimum age for operation. Our series seems to show a bad immediate result in children under the age of 2 years. Otherwise no conclusion can be drawn from our series as to the relation between the age at which the deformity was corrected and the ultimate result. To illustrate this, the ages of the patients with good and bad results in group $\mathbf{A}$ are given (Table VII). 
TABLE VII

\begin{tabular}{|c|c|}
\hline \multicolumn{2}{|c|}{ Result } \\
\hline Good & Bad \\
\hline $\begin{array}{r}10 \mathrm{mth} \\
6 \mathrm{yr} \\
23,, \\
7, ", \\
5,, \\
2,, \\
4, \\
13,, \\
9,, \\
13,,\end{array}$ & $\begin{array}{c}19 \mathrm{mth} \\
17 \text {, } \\
10 \frac{1}{2} \mathrm{yr} \\
2,, \\
5, " \\
14, " \\
4 \frac{1}{2},, \\
25,, \\
25,,\end{array}$ \\
\hline
\end{tabular}

RELATION OF SEX AND RECURRENCE No relation is evident between the ultimate result and the sex of the patient. Eight out of nine bad cases in group A were male, mostly children. The only female case with a recurrence in this group was a girl aged 14 years. On the other hand, out of 10 good results in group $A$ seven were male and three were female. The female cases were aged 13 and 23 years. Again no conclusion can be drawn as to the incidence of recurrence and the sex of the patient.

STERNAL PROMINENCE We have the records of six cases with sternal prominence. These cases are among the eight previously reported from this unit by Chin (1957), and the details are given in Table VIII.

TABLE VIII

\begin{tabular}{|c|c|c|c|c|}
\hline \multirow{2}{*}{ Sex } & \multirow{2}{*}{ Age } & \multirow{2}{*}{ Operation } & \multicolumn{2}{|c|}{ Result } \\
\hline & & & Immediate & Present \\
\hline $\begin{array}{l}\mathbf{M} \\
\mathbf{M} \\
\mathbf{M} \\
\mathbf{M} \\
\mathbf{M} \\
\mathbf{F}\end{array}$ & $\begin{array}{c}20 \\
7 \\
15 \\
6 \frac{1}{2} \\
17 \\
8\end{array}$ & $\begin{array}{l}1956 \\
1957 \\
1956 \\
1956 \\
1954 \\
1955\end{array}$ & 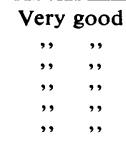 & $\begin{array}{ll}\text { Very good } \\
\text {," } \\
,, & , \\
,, & , \\
,, & ,\end{array}$ \\
\hline
\end{tabular}

The records of the two other cases are too incomplete to be included here, but in one the immediate result was good and in the other bad.

The over-all result is good and better than in patients with pectus excavatum.

\section{CONCLUSION AND SUMMARY}

The chest deformities under consideration in this paper were 58 cases of pectus excavatum and six $\frac{\bar{\rho}}{\bar{\sigma}}$ of sternal prominence (pectus carinatum). The $\stackrel{\mathbb{\Phi}}{\Omega}$ study reveals these points.

(1) The immediate result of a repair of pectus excavatum is generally good, particularly when. the deformity is of a localized and symmetrical $\vec{\omega}$ type (type 1 deformity).

(2) The condition recurs. The process of regres- $-\vec{x}$ sion and recurrence is a progressive one lasting. two to three years. It starts in cases with a good immediate result four to five years after opera- $\omega$ tion ; in cases with a fair immediate result it startso earlier.

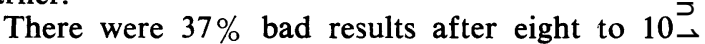
years, but only $11 \%$ after five to seven years. For $ᄃ$ the same period of time there were $41 \%$ good results after eight to 10 years, and $50 \% \operatorname{good}_{\overrightarrow{0}}$ results after five to seven years.

(4) We found no reason why the deformity should recur. No relation was found between ageo and the ultimate result.

(5) The possible aetiology of the condition is discussed. No definite conclusions can be drawn. $\frac{\mathrm{Q}}{\circ}$

(6) The long-term result of surgery in cases with sternal prominence is good, and better than in $\overrightarrow{\overrightarrow{0}}$ cases with sternal depression (pectus excavatum).

I would like to thank Mr. K. S. Mullard for his helpful suggestions, and for allowing me to study the patients under his care.

A number of patients in this review are under the care of Mr. I. K. R. McMillan, and I wish to thanki him for allowing me to include them.

I am also very grateful to Miss J. Le Cornu for secretarial assistance.

\section{REFERENCES} Brodkin, H. A. (1953). Congenital anterior chest wall deformities of
diaphragmatic origin. Dis. Chest, 24, 259 .

Chin, E. F. (1957). Surgery of funnel chest and congenital sternalN prominence. Brit. J. Surg., 44, 360.

Ravitch, M. M. (1949). The operative treatment of pectus excavatum. N Ann. Surg., 129, 429.

(1956). The operative treatment of pectus excavatum. J. Pediat. 48, 465 . 